\title{
Ensino de programação para Olimpíada Brasileira de Informática
}

\author{
Aellison C. T. dos Santos $^{1}$, José A. Monteiro ${ }^{1}$, Karla Cristina T. Machado ${ }^{1}$ \\ Paulo R. Branco Lins ${ }^{1}$, Thaís de Almeida R. Ramos ${ }^{1}$, Leonardo V. Batista ${ }^{1}$ \\ ${ }^{1}$ Departamento de Informática - Universidade Federal da Paraíba (UFPB) \\ CEP - 58.051-900 - João Pessoa - PB - Brazil \\ \{cassimiroaellison, karlactabosa, paulorobertobranco, thaisratis\} @gmail.com, \\ jamonteiro@outlook.com, leonardo@ci.ufpb.br
}

\begin{abstract}
With the outstanding growth of the technology usage, the knowledge in computing and programming has been becoming a vital element in the society, however, many yong people have mistaken ideas about this knowledge, which reflects on the high dropout rate of the courses related to the computing area. This article presents an extension project that aims to teach programming skills to high school students, enabling them to participate of the Brazilian Computer Olympiad, event which allows the students to know more deeply the Computer Science. The participating students showed great satisfaction with the course, having interest in being part of the future editions of the same.
\end{abstract}

Resumo. Com o crescimento vertiginoso do uso da tecnologia, o conhecimento em computação e em programação vem se tornando um elemento vital na sociedade, porém muitos jovens possuem uma ideia equivocada a respeito deste conhecimento, o que reflete na elevada taxa de evasão dos cursos relacionados à área da computação. Este artigo apresenta um projeto de extensão que tem como objetivo ensinar programação para alunos do ensino médio, capacitandoos à participar da Olimpíada Brasileira de Informática, evento que permite que os alunos conheçam mais a fundo a Ciência da Computação. Os alunos participantes demonstraram grande satisfação com os cursos, possuindo interesse na participação de edições posteriores dos mesmos.

\section{Introdução}

A Olimpíada Brasileira de Informática (OBI) é uma competição realizada anualmente, a qual é organizada pela Sociedade Brasileira de Computação (SBC) conjuntamente com o Instituto de Computação da UNICAMP. Com o intuito de estimular desde cedo a prática da programação e o desenvolvimento do raciocínio lógico, a OBI vem conquistando muitos estudantes, e como premiação oferece cursos de lógica e de programação na UNICAMP, além de uma vaga na International Olympiad in Informatics (IOI) para os melhores colocados.

A computação vem adquirindo maior importância a cada dia devido ao crescimento vertiginoso do uso da tecnologia. Entretanto, há uma tendência de queda pela procura dos cursos superiores nesta área.[Cabral 2007]. Os estudantes geralmente produzem uma visão errada do curso de Ciência da Computação, sendo assim, os alunos ao ingressarem na universidade acabam percebendo que o curso não é o que esperavam. Segundo 
uma pesquisa do MEC realizada em 2009, os três cursos com maior índice de evasão são os cursos de Matemática, Ciência da Computação e Administração, sendo o curso de Ciência da Computação o líder do ranking, com 38\% de evasão [Falcão 2009].Esta ocorrência poderia ser reduzida se durante o ensino médio os alunos tivessem uma maior proximidade com a programação. Uma maneira de despertar o interesse de jovens de Ensino Médio para a Computação é por meio da OBI.

Com a pretensão de auxiliar os alunos do Ensino Médio na preparação para a OBI, foram ministrados dois cursos de iniciação a programação. Os dois cursos foram realizados na Universidade Federal da Paraíba (UFPB) e atenderam aos alunos de escolas públicas e privadas do município de João Pessoa. O conteúdo do primeiro curso foi ministrado em cinco aulas abordando temas básicos e introdutórios à programação. Já o assunto do segundo curso foi ministrado também em cinco aulas, porém abordou questões a cerca de técnicas de programação e algoritmos para resolução de questões da OBI.

\section{Materiais e métodos}

O primeiro curso de programação possuiu nível básico e utilizou a ferramenta Scratch, linguagem de programação ideal para pessoas que estão começando a programar, e a linguagem de programação Python. Já o segundo curso, foi motivado pelo interesse dos alunos que fizeram o primeiro, desejando assistir aulas de programação com um nível mais avançado. $\mathrm{O}$ foco foi em algoritmos de resolução de problemas e a linguagem de programação ficou a critério dos alunos, que escolheram entre Python e $\mathrm{C}++$.

\subsection{Metodologia das Aulas}

Aulas expositivas dialogadas tornam o processo de aprendizado mais dinâmico, estimulam a criatividade do aluno e garantem um ambiente de produção de conhecimento, onde o aluno aprende juntamente com o professor [Libâneo 1990], se enquadrando perfeitamente às necessidades deste curso.

As aulas foram ministradas por dois professores, intercaladamente, enquanto outras cinco pessoas atuavam como monitores, tirando dúvidas dos alunos durante as atividades práticas. No primeiro curso, de nível básico, as aulas tinham como objetivo o ensino de programação. Assumindo que os alunos ainda não tinham conhecimento, foi utilizada a ferramenta Scratch como instrumento de inserção de conceitos básicos. O Scratch foi desenvolvido pelo grupo Lifelong Kindergarten no Media Lab do MIT (Instituto de Tecnologia de Massachusetts), e consiste em um ambiente de programação poderoso e de fácil aprendizado, utilizando uma interface de blocos que se encaixam como um quebracabeça para gerar o programa executável. O Scratch foi escolhido por ser uma opção que, além de gratuita, possui uma interface amigável e é perfeita para o primeiro contato com linguagens de programação [Scratch 2015].

As aulas desse curso tiveram duração de duas horas cada, sendo uma aula por semana durante cinco semanas, chegando a um total de dez horas de aula. Cada aula possuiu cerca de uma hora e quinze minutos de parte teórica, seguida de quarenta e cinco minutos de exercícios práticos sobre assuntos abordados durante a aula. Nas duas primeiras aulas, os alunos tiveram seu primeiro contato com programação e algoritmos através do software Scratch, onde foram inseridos conceitos básicos de programação, como: algoritmos, estruturas de repetição e condição, variáveis, iteração etc. Com o Scratch há a vantagem do 



na maioria dos programas básicos das demais linguagens de programação.

$\mathrm{Na}$ terceira e quarta aula foram ensinados conceitos e estruturas da linguagem de programação Python, por meio de exemplos práticos, fazendo referência ao conteúdo já assimilado nas duas primeiras aulas com o auxílio do Scratch, sendo necessária apenas a adaptação à sintaxe da nova linguagem de programação. Os programas em Python foram compilados e executados utilizando a IDE Python IDLE, ferramenta produzida e distribuída pela própria Python Software Foundation, sendo em suma uma aplicação que pode ser usada como um executor de comandos fornecidos na linguagem Python.

$\mathrm{Na}$ última aula foi realizada uma mini-maratona de programação, no qual os alunos foram submetidos a questões de edições anteriores da Olimpíada Brasileira de Informática (OBI).

Já no segundo curso, como as aulas tinham como objetivo acrescentar novos conceitos e refinar as habilidades de programação dos alunos, foram realizadas mudanças quanto à liberdade na escolha da ferramenta de programação e à distribuição de horários, que foram modificadas a fim de permitir que os participantes do curso tivessem o máximo de prática possível, com aulas diárias com duração de duas horas e meia, em um período de cinco dias, totalizando doze horas e meia de aula.

As quatro primeiras aulas foram divididas individualmente entre quarenta e cinco minutos de aula teórica e uma hora e quarenta e cinco minutos de resoluções de exercícios, os quais foram escolhidos cautelosamente para que o aluno pudesse praticar de forma eficiente o que acabou de aprender. O tema das aulas foram: apresentação do curso e conceito de estruturas; matemática aplicada às olimpíadas; pesquisa e ordenação de dados; tratamento de strings.

A última aula seguiu a proposta do curso anterior, realizando uma mini-maratona de programação com questões de níveis mais elevados, comparado com a primeira edição do curso.

Algumas mudanças foram realizadas em relação ao primeiro curso, pois novos alunos foram inseridos e ocorreu uma redução na taxa de evasão dos estudantes. O curso os incentivou à criar o hábito da prática e estudo de programação, atividade fundamental para o treinamento direcionado às olimpíadas.

\subsection{Questionário de Avaliação}

Ao final dos dois cursos, os alunos responderam, individualmente, a um questionário com perguntas relacionadas à qualidade dos cursos e dos materiais. Os questionários também permitiam que os alunos fizessem sugestões, críticas ou reclamações. Algumas questões eram específicas para o primeiro curso e outras para o segundo. Os dois questionários eram compostos por sete questões, sendo as duas primeiras perguntas específicas de cada curso.

Em relação ao primeiro curso, a primeira questão perguntava se os alunos possuíam interesse em participar de um curso de programação com conteúdos mais avançados e a segunda questão perguntava se os alunos acharam que a utilização da ferramenta

\footnotetext{
${ }^{1}$ Imagem ou objeto gráfico utilizado em animações, jogos ou aplicações feitas computacionalmente.
} 
Scratch ajudou a desenvolver o conceito da lógica de programação.

Já em relação ao segundo curso, a primeira pergunta indagava se os alunos sentiam-se seguros em fazer a prova da OBI depois de ter participado do curso, e a segunda pergunta desejava saber se os alunos agregaram algum conhecimento com o curso.

As cinco perguntas restantes dos dois questionários foram dividas em questões de múltipla escolha e questões dissertativas. Assim, a terceira questão de ambos os questionários pedia para que os alunos classificassem a forma com que o conteúdo foi ministrado; a quarta questão perguntava o que os alunos acharam da duração das aulas; a quinta questão perguntava se os alunos ficaram satisfeitos com a quantidade de aulas ministradas; a sexta questão gostaria de saber se o aluno tinha alguma sugestão para as próximas edições do curso; e a última questão pedia que o aluno informasse alguma reclamação ou observação a respeito do curso.

\section{Resultados}

Como consequência da análise dos questionários dos dois cursos realizados com os alunos de ensino médio foram observadas, primeiramente, questões metodológicas de ensino que dizem respeito à forma como o conteúdo foi lecionado (Figura 1(a)). Neste quesito constatamos uma avaliação positiva de $100 \%$ dos alunos dos dois cursos entre os graus de nivelamento bom e ótimo.

No quesito de tempo de duração das aulas, ambos os cursos obtiveram uma avaliação considerada mediana, onde porções significativas de alunos assinalaram graus de nivelamento abaixo da categoria bom (Figura 1(b)). Tal fato pode ser entendido por motivos como indisponibilidade dos laboratórios, já que os mesmos atendem às demandas dos três cursos de bacharelado (Ciência da Computação, Engenharia da Computação e Matemática Computacional) do Centro de Informática da UFPB.



(a)

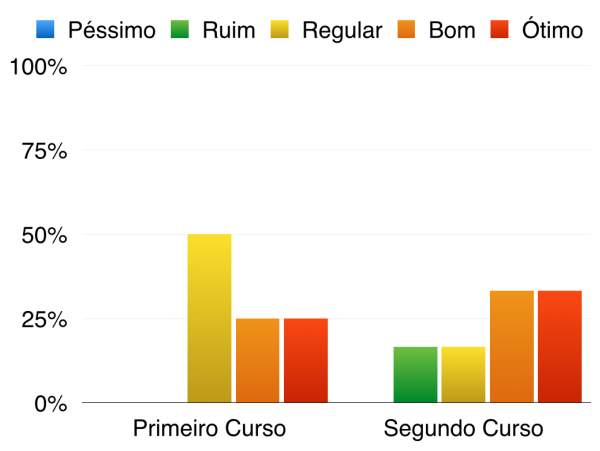

(b)

Figura 1. Gráfico demonstrativo da avaliação da metodologia de ensino aplicada (a) e do tempo de duração das aulas (b).

Quando questionados sobre a quantidade de aulas dos dois cursos, a maior parte dos alunos julgou que o total de aulas definido deveria ser maior (Figura 2(a)), negativando assim a avaliação desse quesito no geral.

Entretanto, a ideia de participar de um curso de programação com conteúdos mais avançados foi bem aceita pelos alunos (Figura 2(b)). O que pôde ser constatado, inclusive, durante as próprias aulas por meio de comentários dos alunos. 


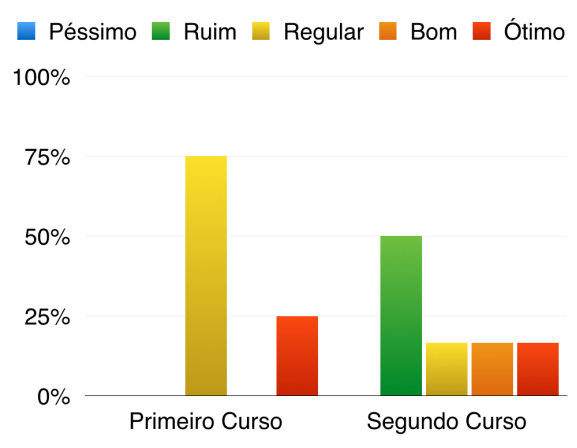

(a)

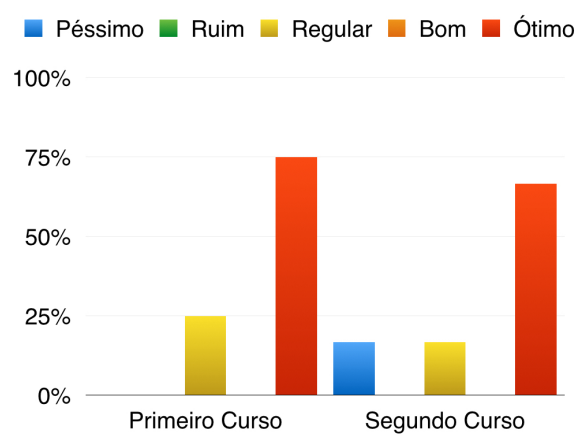

(b)

Figura 2. Gráfico demonstrativo da avaliação da quantidade de aulas (a) e da ideia de participar de um curso avançado de programação (b).

Focando separadamente na análise do primeiro e segundo cursos, a avaliação da ferramenta Scratch obteve um resultado satisfatório, pois 50\% dos alunos a classificou como sendo uma boa ferramenta introdutória. Já em relação ao sentimento de segurança por parte dos alunos em participar da OBI, foi avaliado que cerca de $67 \%$ dos alunos classificaram que estariam seguros para realizar a prova.

Assim, os dois cursos que possuíam como resultado esperado incentivar à prática de programação dos alunos de ensino médio, atingiram, numa visão geral, bons números para a primeira edição do projeto de extensão.

\section{Conclusão}

Durante a realização dos cursos, foi perceptível a grande evolução de cada um dos alunos. Sendo assim, foi estabelecida a manutenção da atividade para os próximos semestres. Além disto, os alunos participantes foram estimulados a continuar com a prática da programação, pois esta é uma atividade de grande estímulo ao raciocínio lógico.

Com estes cursos, foi possível perceber os assuntos que os alunos encontraram mais dificuldade e as metodologias mais fluentes para esse público em específico, construindo uma base sólida para a realização das próximas edições.

Apesar da duração e quantidade de aulas receberem avaliação negativa, foi possível perceber o quanto as aulas foram importantes para o público alvo. Mostrando que quando a computação é inserida de maneira correta, é possível gerar futuros graduandos que realmente sabem do que se tratam os cursos da área.

\section{Referências}

Cabral, M. I. C. e. a. (2007). Perfil dos cursos de informática no brasil. WIE.

Falcão, L. F. (2009). Desistência de estudantes preocupa instituições. http://imirante.globo.com/sao-luis/noticias/2009/04/16/desistencia-de-estudantespreocupa-instituicoes.shtml.

Libâneo, J. C. (1990). Didática. Editora Cortez, São Paulo.

Scratch (2015). Scratch program. http://wiki.scratch.mit.edu/wiki/Scratch ${ }_{P}$ rogram. 